\title{
Origins and Neurochemical Complexity of Preganglionic Neurons Supplying the Superior Cervical Ganglion in the Domestic Pig
}

\author{
Judyta K. Juranek • Joanna A. Wojtkiewicz
}

Received: 14 March 2014 / Accepted: 29 April 2014 / Published online: 23 May 2014

(C) The Author(s) 2014. This article is published with open access at Springerlink.com

\begin{abstract}
The superior cervical ganglion (SCG) is a center of sympathetic innervation of all head and neck organs. SCG sympathetic preganglionic neurons (SPN) were found in the nucleus intermediolateralis pars principalis (IMLpp), the nucleus intermediolateralis pars funicularis (IMLpf), the nucleus intercalatus spinalis (IC), and the nucleus intercalatus spinalis pars paraependymalis (ICpe). Despite its importance, little is known of SCG innervation and chemical coding in the laboratory pig, a model that is physiologically and anatomically representative of humans. Here in our study, we established the distribution and chemical coding of Fast Blue (FB) retrogradely labelled SPN innervating porcine SCG. After unilateral injection of FB retrograde tracer into the left SCG, labeled neurons were found solely on the ipsilateral side with approximately $98 \%$ located in $\mathrm{Th}_{1}-\mathrm{Th}_{3}$ segments and predominantly distributed in the IMLpp and IMLpf. Neurochemical analysis revealed that approximately $80 \%$ of SPN were positive both to choline acetyltransferase (ChAT) and nitric oxide synthase (NOS) and were surrounded by a plethora of opioidergic and peptiergic nerve terminals. The results of our study provide a
\end{abstract}

J. K. Juranek $(\bowtie)$

Department of Medicine, New York University Medical Center, 550

First Avenue, Smilow 906, New York, NY, USA

e-mail: judytajuranek@gmail.com

J. A. Wojtkiewicz

Department of Pathophysiology, University of Warmia and Mazury, Olsztyn, Poland

J. A. Wojtkiewicz $(\bowtie)$

Department of Neurology and Neurosurgery, Division of

Neurosurgery, University of Warmia and Mazury, Ul. Warszawska

30, 10-082 Olsztyn, Poland

e-mail: joanna.wojtkiewicz@uwm.edu.pl

J. A. Wojtkiewicz

Stem Cell Research Laboratory, Faculty of Medical Sciences,

University of Warmia and Mazury, Olsztyn, Poland detailed description of the porcine preganglionic neuroarchitecture of neurons controlling the SCG, setting the stage for further studies concerning SPN plasticity under experimental/pathological conditions.

Keywords Sympathetic preganglionic neurons · Superior cervical ganglion · Domestic pig · Retrograde tracing · Neurochemical coding

\section{Introduction}

The superior cervical ganglion (SCG) is the center of sympathetic innervation of all head and neck organs. It provides sympathetic input to numerous key organs and structures such as the salivary glands, pineal gland, thyroid, carotid body, choroid plexus, brain and cranial muscle vasculature, eyes, and lacrimal gland, thus playing a vital role in a number of neuroendocrine, visceral, or vision-related processes (Cardinali et al. 1983). Studies showed that SCG is involved in circadian rhythm regulation (Lingappa and Zigmond 2013), thyroid function modulation (Young et al. 2005), tear production (Ding et al. 2003; Tangkrisanavinont 1984), skin vasoconstriction (Gibbins et al. 1998), and cerebral arterial supply regulation (Arbab et al. 1986; Cassaglia et al. 2008; Goadsby 2013). Despite being considered a small neuroendocrine center (Cardinali et al. 1983), a complex neurochemical phenotype of its preganglionic neurons and fibers has yet to be completed.

In animal models studied so far, sympathetic preganglionic neurons (SPN) supplying the SCG were found in cervicothoracic neuromeres, which were confined to the following nuclei: (1) nucleus intermediolateralis pars principalis (IMLpp), (2) nucleus intermediolateralis pars funicularis (IMLpf), (3) nucleus intercalatus spinalis (IC), and (4) nucleus intercalatus spinalis pars paraependymalis (ICpe) (Dalsgaard 
and Elfvin 1979; Petras and Faden 1978; Yau et al. 1991); however, until now there is no data clarifying the origins of porcine SCG innervation.

Studies conducted in laboratory animals show that the chemical phenotype of these neurons is very diverse and complex, underscoring the importance of the ganglion in autonomic regulation. Acetylcholine (ACh) is the main SPN neurotransmitter; however, studies show that its actions upon SCG activity are largely supported by nitric oxide (NO) present in preganglionic neurons alongside ACh (Okamura et al. 1995).

It has been shown that NO modulates cyclic GMP synthesis in cholinergic neurons, affecting ACh release from these neurons and thus regulating overall ACh activity (Prast et al. 1995).

Furthermore, data obtained from human and small animal laboratory species reveal that aside from $\mathrm{ACh}$ and $\mathrm{NO}$, a number of other neuromodulatory substances such as serotonin (Jensen et al. 1995), leu-enkephalin (Klimaschewski et al. 1995), pituitary adenylate cyclase-activating polypeptide (PACAP) (Beaudet et al. 1998), neuropeptide (NPY), calcitonin gene-related peptide (CGRP) (Yamamoto et al. 1989), substance P (SP) (Klimaschewski et al. 1995; LlewellynSmith et al. 1997; Tan et al. 1996), and vasoactive intestinal peptide (VIP) (Sasek et al. 1991) are present in the SCGinnervating preganglionic neurons, likely contributing to the SCG neuroendocrine function.

Here in the present study, we investigated the distribution and neurochemical coding of SCG supplying neurons in the pig, an animal model physiologically and anatomically similar to humans. In our previous study, we showed a complete 2D reconstruction of porcine SCG and provided neurochemical characteristics of SCG neurons supplying the porcine parotid gland (Wojtkiewicz et al. 2011). In this project, we have advanced in our research, paving the way to the source of SCG innervation and providing a detailed overview of SCG preganglionic neuron distribution and their complex neurochemical phenotype.

\section{Materials and Methods}

Six 8-week-old female pigs of the Large White Polish breed, weighing ca. $20-25 \mathrm{~kg}$, were used in the study. The animals were housed in accordance with the principles of Laboratory Animal Care (NIH publication no. 86-23, revised 1985) and approved by the Ethical Commission of Veterinary Medicine Faculty at the University of Warmia and Mazury, Olsztyn, Poland (Resolution No. 47/2006). The animals were preanesthetized with propionyl promazine $(0.4 \mathrm{mg} / \mathrm{kg} \mathrm{b} / \mathrm{w}$, i.m.) and deeply anesthetized with sodium barbital $(25 \mathrm{mg} /$ $\mathrm{kg} \mathrm{b} / \mathrm{w}$; i.v.). The left SCG, exposed via midline neck incision, was injected with retrograde tracer, Fast Blue (FB, EMS, Grivory, Deutschland, GMbH, Postfach) at multiple sites along the SCG. Injections were given with a Hamilton microsyringe at a total volume of $20 \mu \mathrm{l} 5 \%$ dye solution ( $1 \mu$ l dye solution per injection). After a 3 -week survival time, animals were re-anesthetized and sacrificed by an overdose of pentobarbital. Following sacrifice, animals were perfused transcardially with heparinized physiological saline in 0.1 phosphate buffer (PB, pH 7.4) and fixative solution containing $4 \%$ paraformaldehyde $0.1 \mathrm{M} \mathrm{PB}(\mathrm{pH} 7.4)$. Immediately after perfusion, spinal cord $\mathrm{C} 5-\mathrm{Th} 8$ segments were exposed by laminectomy and dissected. The segments were immersed in the same fixative for $20 \mathrm{~min}$ and stored in $18 \%$ phosphatebuffered sucrose solution for further processing. The spinal cord segments were sectioned transversally $(n=3)$ and longitudinally $(n=3)$ on the cryostat at $10 \mu \mathrm{m}$ in thickness, mounted on glass slides, and stored at $70{ }^{\circ} \mathrm{C}$.

Immunofluorescent staining was performed according to standard procedure as described (Wojtkiewicz et al. 2011). Briefly, $10-\mu \mathrm{m}$-thick cryostat sections were air-dried at RT for $45 \mathrm{~min}$ and rinsed $(3 \times 15 \mathrm{~min})$ with phosphate-buffered saline (PBS, pH 7.4). Afterwards, the samples were incubated with a blocking mixture containing $1 \%$ Triton X-100 (SigmaAldrich, USA), $0.1 \%$ bovine serum albumin (SigmaAldrich, USA), $0.05 \%$ thimerosal (Sigma-Aldrich, USA), $0.01 \% \mathrm{NaN}_{3}$, and $10 \%$ of normal goat serum (MP Biomedicals, USA) in $0.01 \mathrm{M}$ phosphate-buffered saline for $1 \mathrm{~h}$ at RT, rinsed in PBS ( $3 \times 15 \mathrm{~min})$, and incubated overnight with the following primary antibodies: mouse anti-nitric oxide synthase (NOS), co-stained with an array of rabbit antisera against dynorphin A (DYN A), Leu-5 enkephalin (LENK), neuropeptide Y (NPY), $\alpha$-neoendorphin $(\alpha \mathrm{NEO})$, calbindin D-28 k (CB-D28k), calretinin (CRT), galanin (GAL), vasoactive intestinal peptide (VIP), peptide histidine-isoleucine (PHI-27), vesicular acetylcholine transporter (VAChT), substance P (SP), calcitonin gene-related peptide (CGRP), pituitary adenylate cyclase-activating peptide-27 (PACAP-27), somatostatin (SOM), choline acetyltransferase (ChAT), serotonin (5-HT), cholecystokinin (CCK), cocaine- and amphetamine-regulated transcript (CART), and GABA (for dilutions and secondary antibodies, see Table 1). Sections were then incubated with a mixture of appropriate fluorescein isothiocyanate (FITC)-conjugated secondary antisera and biotinylated goat anti-rabbit antibodies $(1 \mathrm{~h})$. The latter antibodies were visualized by additional incubation of sections with streptavidin-CY3 complex $(1 \mathrm{~h})$. After staining, the sections were mounted with carbonate-buffered glycerol $(\mathrm{pH}$ 8.6) and cover slipped. The specificity of primary antisera was tested as follows: sections were incubated with antibody, preabsorbed with synthetic antigen $(10 \mu \mathrm{g}$ of antigen $/ \mathrm{ml}$ diluted antiserum); the primary antibody was omitted from the incubation; or normal rabbit or mouse serum was substituted for the primary antibody.

Sections were examined under an Olympus BX51 fluorescence microscope equipped with a barrier filter for FB. Microphotographs were acquired with a CCD camera 
Table 1 Detailed list of primary and secondary antibodies used in the study

\begin{tabular}{|c|c|c|c|c|c|}
\hline Antisera & Reagent & Code & Host Species & Dilution & Supplier \\
\hline \multicolumn{6}{|c|}{ Primary antibodies } \\
\hline ChAT & & AB5052 & Rabbit & $1: 10,000$ & Chemicon Int. Inc, UK; www.chemicon.com \\
\hline NPY & & NA 1233 & Rabbit & $1: 10,000$ & Biomol Res. Lab. Inc, US; www.biomol.com \\
\hline SOM & & $8330-0154$ & Rabbit & $1: 10,000$ & Biogenesis Inc, www.biogenesis.co.uk \\
\hline VIP & & 11428 & Rabbit & $1: 10,000$ & MP Biomedicals; www.mpbio.com \\
\hline GAL & & RIN7153 & Rabbit & $1: 10,000$ & Bachem AG; www.bachem.com \\
\hline CB-D28k & & CB-38 & Rabbit & $1: 10,000$ & SWANT, S; www.swant.com \\
\hline CRT & & $7699 / 4$ & Rabbit & $1: 20,000$ & SWANT, S; www.swant.com \\
\hline NOS & & $\mathrm{N} 2280$ & Mouse & $1: 2,000$ & Sigma; http://www.sigmaaldrich.com \\
\hline LENK & & EA 1149 & Rabbit & $1: 10,000$ & BioReagents Inc, UK; www.bioreagents.com \\
\hline DYNA & & S-4019 & Rabbit & 1: 10,000 & Bachem AG; www.bachem.com \\
\hline$\alpha \mathrm{NEO}$ & & S-3149 & Rabbit & $1: 10,000$ & Bachem AG; www.bachem.com \\
\hline VAChT & & H-V006 & Rabbit & $1: 10,000$ & Phoenix,; www.phoenixpeptide.com \\
\hline PACAP & & IHC 8922 & Rabbit & $1: 20,000$ & Bachem AG; www.bachem.com \\
\hline PHI & & S-3130 & Rabbit & $1: 10,000$ & Bachem AG; www.bachem.com \\
\hline CGRP & & 11189 & Rabbit & $1: 10,000$ & MP Biomedicals; www.mpbio.com \\
\hline SP & & $8450-0505$ & Rabbit & $1: 10,000$ & Biogenesis Inc, www.biogenesis.co.uk \\
\hline $5 \mathrm{HT}$ & & S5545 & Rabbit & $1: 5,000$ & Sigma, US; www.sigma-aldrich.com \\
\hline \multicolumn{6}{|c|}{ Secondary antibodies } \\
\hline & $\begin{array}{l}\text { Donkey anti-mouse IgG }(\mathrm{H}+\mathrm{L}) \\
\text { conjugated with FITC }\end{array}$ & & & $1: 800$ & 715-095-151; Jackson IR Lab, US; www.jacksonimmuno.com \\
\hline & $\begin{array}{l}\text { CY3-conjugated } \mathrm{F}\left(\mathrm{ab}^{\prime}\right)_{2} \text { donkey } \\
\text { anti-rabbit } \operatorname{IgG}(\mathrm{H}+\mathrm{L}) \text { - }\end{array}$ & & & $1: 9,000$ & 711-166-152, Jackson IR Lab, US; www.jacksonimmuno.com \\
\hline
\end{tabular}

connected to a PC equipped with AnalySIS image analysis software (ver. 3.2; Soft Imaging System GmbH, Münster, Germany). To determine the relative number of FB-positive cells, neurons were counted in every 16 th section at $\times 20$ objective. Only neurons with a clearly visible nucleus were considered. Data was pooled from animals and analyzed with GraphPad Prism 5 software (GraphPad Software, La Jolla, CA, USA). Results are presented as means \pm standard error of mean (SEM). Nerve fiber distribution was assessed under $\times 40$ objective by subjective observation (two independent researchers) as previously described (Gonkowski et al. 2013) and depending on the density of labeling, described as not found or very few, small, moderate, and large number of nerve fibers.

\section{Results}

Following FB injections of left SCG, FB-positive neurons were found on the ipsilateral side of the spinal cord. A total of 13,013 neurons, combined from longitudinal and transverse sections, were counted. The sympathetic preganglionic neurons (SPN) projecting to the porcine SCG were found in C8 to Th6 neuromeres, with the vast majority of them located in Th1-Th3 segments $(94 \pm 4.4 \%$ ), ranging from $27.6 \pm 3.0 \%$ (Th1) to $34.5 \pm$ $4.0 \%$ (Th2) and $31.6 \pm 6.3 \%$ (Th3), respectively.

FB neurons were localized predominantly in IMLpp (85.9 $\pm 2.4 \%$; 4,313 cells $)$ and IMLpf $(9.0 \pm 1.5 \%$; 451 cells $)$ and about $5 \%$ of the cells were seen in ICpe $(0.5 \pm 0.2 \% ; 23$ cells $)$. ChAT-, NOS-, VAChT-, CRT-, CB-D28k-, SOM-, PACAP-, and $\mathrm{CCK}$-immunoreactive $\mathrm{FB}^{+}$neurons constituted approximately $88,72,7,3.5,3,3,1$, and $0.6 \%$ of all $\mathrm{FB}$ neurons in the whole region, respectively. The largest population of $\mathrm{FB}+/$ $\mathrm{NOS}+$ neurons was positive for ChAT $(62.8 \pm 4.9 \%)$, followed by a much smaller number of VAChT $(5.3 \pm 2.7 \%)$-positive neurons. A few of the FB-positive nitrergic neurons also contained CB-28 k (2.2 \pm 0.4$)$, SOM $(2.0 \pm 0.7 \%)$, and PACAP $(1.0 \pm 0.5 \%)$ and a very limited number of $\mathrm{FB}+/$ $\mathrm{NOS}+$ neurons were positive to CCK $(0.6 \pm 0.4 \%)$ and CRT $(0.6 \pm 0.4 \%)$ (Table 2; Figs 1 and 2). None of the FB-positive perikarya was immunopositive to LENK, SP, PHI, NPY, VIP, GAL, CGRP, 5HT, and $\alpha$-NEO. Retrogradely labelled SPN were surrounded by a very dense network of opioidergic (LENK-, DYN A-, or $\alpha$-NEO-IR), GABA-, PACAP-, CART-, or VAChT-IR nerve terminals, a moderately dense network of SP-, SOM-, CALB-, CRT-, or TH-IR nerve fibers, and a scarce network of CCK-, VIP-, PHI-, NPY-, 5HT-, GAL-, or CGRP-IR axons (Figs. 1 and 2). 


\section{Discussion}

Our results show that the majority of all neurons supplying SCG is localized between first through third spinal cord thoracic segments $\left(\mathrm{TH}_{1-3}\right)$ and originates predominantly from nucleus intermediolateralis pars principalis and pars funicularis with only a small percentage found elsewhere, that is, in nucleus intercalatus spinalis pars paraependymali. These results are consistent with data obtained from other species (Dalsgaard and Elfvin 1979; Petras and Faden 1978; Yau et al. 1991) and provide further evidence establishing the predominant importance of intermediolateral nuclei in SCG innervation. The observation bears clinical relevance as intermediolateral column injury apparently disrupts SCG function, subsequently resulting in various vascular, respiratory, and cardiac dysfunctions (Grigorean et al. 2009; Krassioukov 2009; Popa et al. 2010). It has been shown that sympathetic IML morphological abnormalities in $\mathrm{Th}_{1-3}$ segments observed in patients with familiar dysautonomia lead to SCG shrinkage and activity suppression, resulting in numerous autonomic dysfunctions such as difficulties in swallowing, paresthesia, frequent vomiting, labile hypertension, propensity to lung infections, and corneal problems (Pearson and Pytel 1978); these findings further support the notion of central role of SCG in the autonomic coordination of major vital organs.

Further, our study revealed that the neurochemical composition of neurons supplying SCG is complex, underscoring the importance of this ganglion as a neuroendocrine center. First, we found that the majority of SCG preganglionic neurons is positive to both ChAT and NOS, showing a much higher level of colocalization than previously observed (Blottner and Baumgarten 1992; Calka et al. 2008).

ChAT, an acetylcholine marker, previously reported in the intermediolateral (IML) nuclei of several species (Całka et al. 2008; Ichikawa and Shimizu 1998; Markham and Vaughn 1990) is an important player in numerous neuromodulatory functions (Oda 1999). It has been found that disturbance in neuronal ChAT levels contributes to the mechanisms' underlying development of certain neurodegenerative diseases such as Alzheimer's or Huntington's disorder, schizophrenia, or amyotrophic lateral sclerosis (Oda 1999). NOS, an indicator of nitric oxide presence in the neuron, was shown in the IML nuclei of a number of small and large laboratory animals as well as in humans (Calka et al. 2008; Foster and Phelps 2000; Lopez-Figueroa et al. 1996; Okamura et al. 1995; Reuss and Reuss 2001). It has been shown that NOS is involved in the regulation of several metabolic pathways such as soluble guanylyl cyclase or ADP-ribosyltransferase activation (Blottner and Baumgarten 1992) and, most importantly, modulates acetylcholine neurotransmission in central nervous system neurons affecting their activity (Prast and Philippu 2001). To date, only a few studies have indicated that in the IML
Table 2 Percentages of retrogradely labelled cells in sympathetic preganglionic neurons (SPN; in neuromers Th1-Th3) projecting to the porcine SCG

\begin{tabular}{lllll}
\hline Substance & $\begin{array}{l}\mathrm{FB}^{+} / \mathrm{NOS}^{+} \\
/ \mathrm{P}^{+}\end{array}$ & $\begin{array}{l}\mathrm{FB}^{+} / \mathrm{NOS}^{+} \\
/ \mathrm{P}^{-}\end{array}$ & $\begin{array}{l}\mathrm{FB}^{+} / \mathrm{NOS}^{-} \\
/ \mathrm{P}^{+}\end{array}$ & $\begin{array}{l}\mathrm{FB}^{+} / \mathrm{NOS}^{-} \\
/ \mathrm{P}^{-}\end{array}$ \\
\hline ChAT & $62.8 \pm 4.9$ & $10.8 \pm 1.2$ & $16.2 \pm 3.2$ & $10.6 \pm 1.4$ \\
VAChT & $5.3 \pm 2.7$ & $65.9 \pm 5.3$ & $2.1 \pm 1.1$ & $26.1 \pm 5.7$ \\
CB-28 k & $2.2 \pm 0.4$ & $64.3 \pm 4.5$ & $0.8 \pm 0.5$ & $32.6 \pm 4.9$ \\
SOM & $2.0 \pm 0.7$ & $67.5 \pm 1.3$ & $0.8 \pm 0.2$ & $29.7 \pm 1.5$ \\
PACAP & $1.0 \pm 0.5$ & $66.0 \pm 3.9$ & $0.2 \pm 0.2$ & $32.7 \pm 3.4$ \\
CCK & $0.6 \pm 0.4$ & $67.1 \pm 3.5$ & 0 & $32.4 \pm 3.6$ \\
CRT & $0.6 \pm 0.2$ & $65.1 \pm 5.7$ & $2.9 \pm 1.2$ & $31.3 \pm 5.3$ \\
\hline
\end{tabular}

$\mathrm{P}$ —substance (ChAT, VAChT, PACAP........). Data expressed as mean \pm standard deviation (SD)

column, NOS and ChAT co-exist in the same neurons (Burnett et al. 1995; Całka et al. 2008; Elfvin et al. 1997). It is plausible to assume that both NOS and ChAT play a vital role in the SCG preganglionic neurons, complementing each other's functions and synergistically modulating neuronal activity of autonomic nervous system cells. Interestingly, VAChT, an acetylcholine transporter and another marker of cholinergic neurons, has been found in only $7 \%$ of all SCG supplying neurons. This discrepancy between ChAT and VAChT distribution in cholinergic neurons might be explained by the differential genetic expression and diverse functional patterns of these two molecules at the molecular level (Weihe and Eiden 2000). ChAT and VAChT share the same genetic locus (Eiden 1998); however, it has been established that their expression levels might substantially differ and, depending on neuronal region and developmental stage, do not always correlate (Schutz et al. 2001), as observed in our study.

Furthermore, aside from ChAT, NOS, and VACHT, here for the first time we show the presence of a number of other neurochemicals such as CRT, CB-D28k, SOM, PACAP, and $\mathrm{CCK}$ in IML neurons innervating the SCG, indicating that these neurons largely contribute to and play an important role in maintaining the role of the SCG as a neuroendocrine center.

CRT has been identified in IML preganglionic sympathetic neurons of the rat (Murphy et al. 2003; Ren and Ruda 1994), mouse (Ninomiya et al. 1993), cat (Edwards et al. 1996), and lizard (gecko) (Morona et al. 2006). It belongs to the family of calcium-binding proteins and is involved in a wide array of processes from intracellular calcium signaling through molecular protein targeting to long-time potentiation modification (Schwaller 2014). It is also thought to be involved in neuroprotection, neuronal development, and homeostasis (Barinka and Druga 2010; Schwaller 2014). In the sympathetic nervous system, CRT is presumed to function as a regulator of sympathetic ganglion activity and as a potential contributor to agerelated changes of target organ functions (Corns et al. 2000; Huerta et al. 1996). 

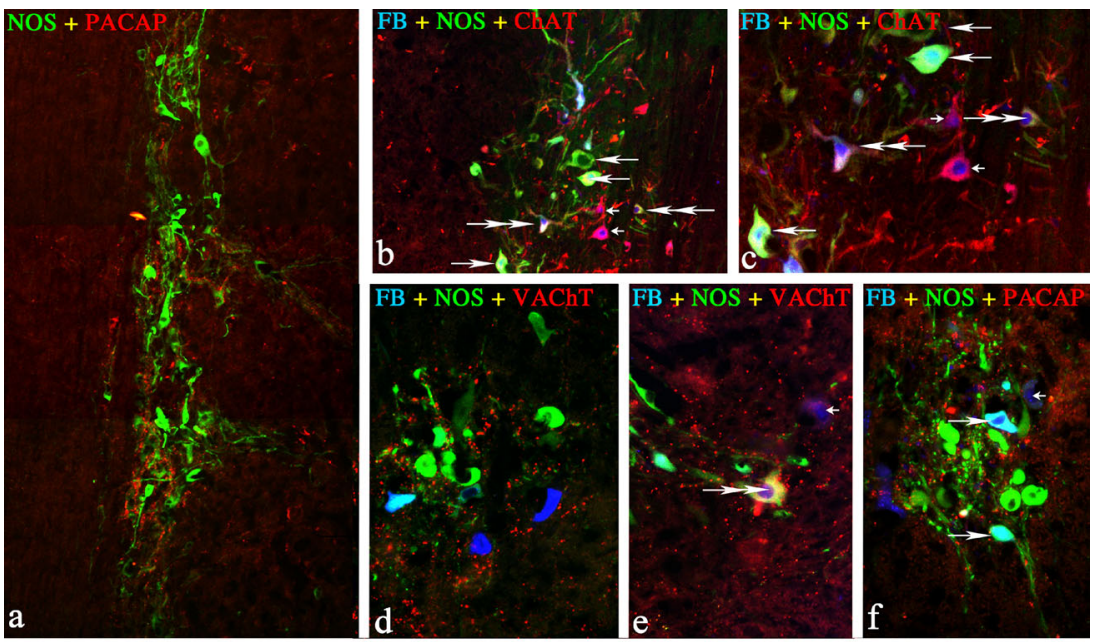
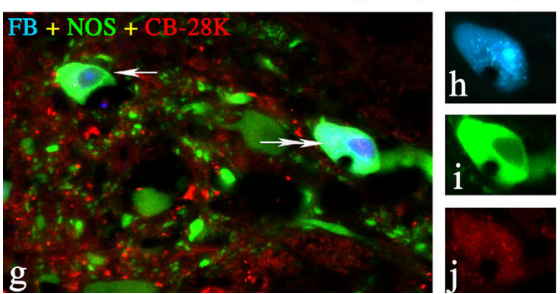

Fig. 1 Representative images of SCG-projecting neurons located in the spinal cord IML column. All pictures are composites of merged images taken separately from the red, green, and/or blue fluorescent channels. a Double-labelled NOS+/PACAP + neurons in the Th3 neuromere, a compilation of three photos. b, $\mathbf{c}$ Three different populations of NOS/ ChAT-positive neurons in Th3 neuromere; $\mathrm{FB}^{+} / \mathrm{NOS}^{+}$neurons positive for ChAT (two double arrows), $\mathrm{FB}+\mathrm{NOS}+$ negative for ChAT (three long arrows), and double-labeled $\mathrm{FB}^{+} / \mathrm{ChAT}^{+}$negative for NOS (two small arrows). d, e Single FB + neurons scattered between a small population of $\mathrm{FB}^{+} / \mathrm{NOS}^{+} / \mathrm{VAChT}+$ (triple staining, two double arrows) and $\mathrm{FB}+/ \mathrm{VAChT}+$ neurons (small arrow). $\mathbf{f}$ A population of double $\mathrm{FB}^{+} /$

$\mathrm{CB}$, another member of the calcium-binding protein family, has been reported in the sympathetic preganglionic neurons of the rat's IML column (Grkovic and Anderson 1997). In the sympathetic nervous system, $\mathrm{CB}$ has been speculated to contribute to the secretory functions of salivary glands and fatty brown tissues (Grkovic and Anderson 1997), play a role in the development of the enteric nervous system (Hagl et al. 2013), and contribute to the pathogenesis of proliferative enteropathy (Wojtkiewicz et al. 2012); however, its exact role has yet to be described. Recent studies indicate that $\mathrm{CB}$ may also play a role in excitatory activity of GABA and glutamate neurons projecting to IML sympathetic preganglionic neurons (Llewellyn-Smith et al. 2002), affecting their function.

$\mathrm{CCK}$, first described as an intestinal hormone (Chandra and Liddle 2007), reported previously in rat, human, and guinea pig sympathetic neurons of IML nuclei (Chiba and Masuko 1987; Chung et al. 1989; Schroder 1983), has been shown to participate in a number of gastrointestinal processes, affecting the activity of numerous digestive system organs, i.e., stomach, gall bladder, pancreas, and intestines (Chandra and Liddle 2007). Studies have shown that changes in CCK expression or a reduction in a $>$ number of CCK receptors contributes to various gastrointestinal and metabolic diseases such as diabetes mellitus, gall stone disease and irritable bowel syndrome (Chandra and Liddle 2007).

SOM, observed previously in the IML column of the guinea pig spinal cord (Chiba and Masuko 1989), has been shown to modulate inflammatory response between neuronal and mast cells in the intestine (Van Op den bosch et al. 2009) and likely acts alongside CCK in digestion and food intake (Schmidt et al. 1994; Zavros et al. 1998). It has been demonstrated that in the sympathetic nervous system SOM affects vasodepressor response (Rioux et al. 1981) and gastrin secretion (Olesen et al. 1984) and that it plays a role in insulin release (Lechin et al. 2013). It might be speculated that in the SCG, SOM plays a regulatory role, affecting the function of SCG target organs. 

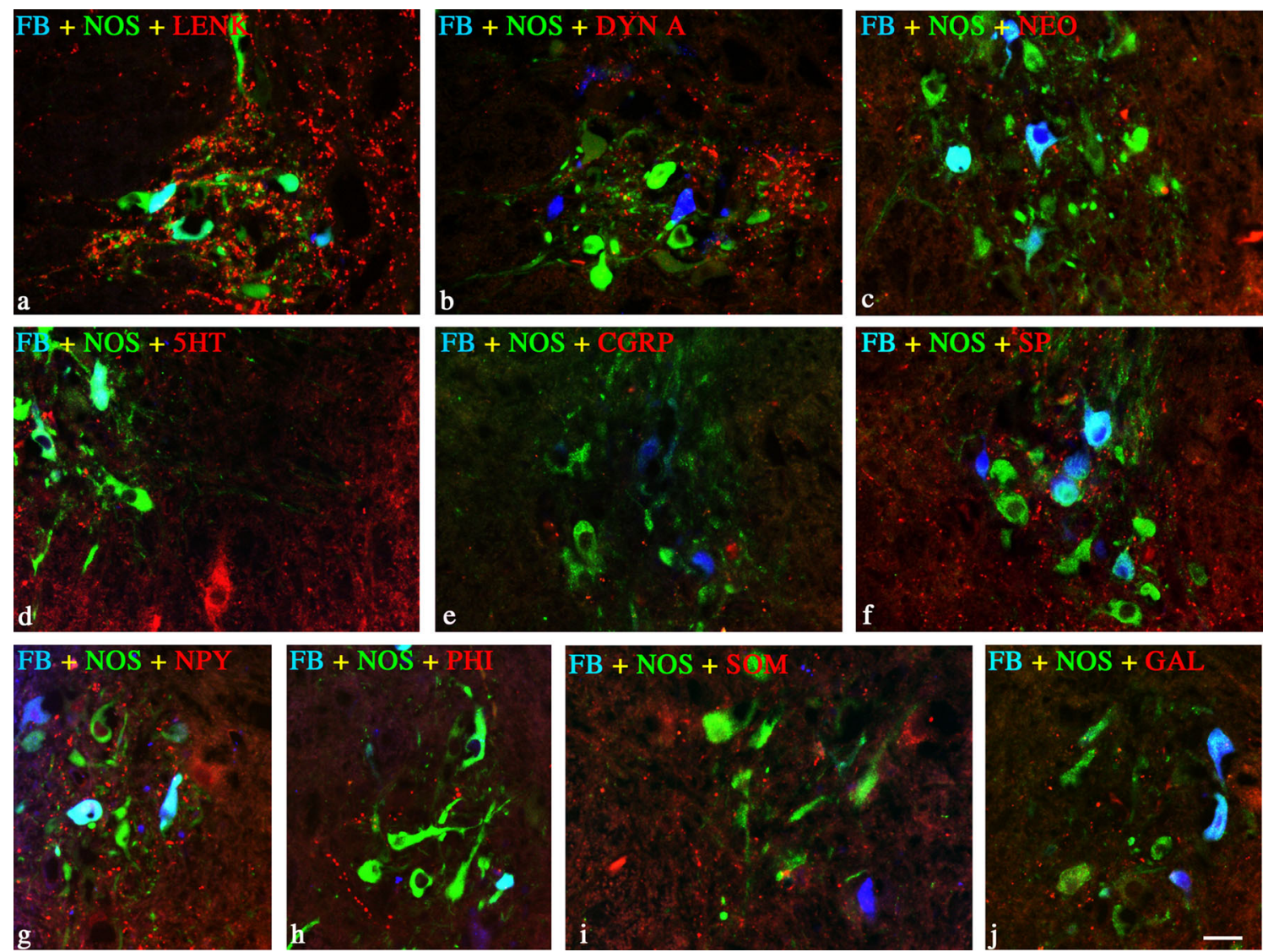

Fig. 2 a - j Representative images of SCG-projecting FB+/NOS + neurons (SPN) and surrounding fibers observed in Th3 neuromere. All images are composites of merged images taken separately from the red,

green, and blue fluorescent channels. Retrogradely labelled SPN were surrounded by a LENK-, b DYN A-, $\mathbf{c} \alpha$-NEO-IR, d 5HT-, e CGRP-, $\mathbf{f}$ SP-, g NPY-, h PHI-, i SOM-, j GAL-IR axons; scale bar $50 \mu \mathrm{m}$

Finally, PACAP, previously found in SCG neurons of the IML column in the rat (Beaudet et al. 1998; Klimaschewski et al. 1996), is critically important in an array of autonomic nervous system-regulated activities, from metabolic and cardiovascular regulation through hormone secretion, stress response to appetite suppression, and food intake regulation (Merriam et al. 2013; Roy et al. 2013; Tanida et al. 2013). It has been shown that in the sympathetic nervous system, PACAP contributes to the neuronal development of the sympathetic neuroblast ( $\mathrm{Lu}$, et al., 1998) and modulates sympathetic neuron function via IP3, cyclic AMP/PKA, and MAPK/ERK regulatory pathways (Girard et al. 2004; May et al. 2000; Merriam et al. 2013). Furthermore, PACAP contributes to NPY and catecholamine expression in SCG neurons by regulating the mRNA levels of these neurotransmitters, thus affecting the function of this ganglion overall (Braas and May 1999; May and Braas 1995).

In addition to numerous neurochemicals present in SCG-projecting neurons, we found a dense network of neurochemically complex fibers surrounding the neurons and containing a plethora of neuropeptides such as LENK, DYN A, $\alpha$-NEO, GABA, PACAP, CART, VAChT, SP, SOM, CALB, CRT, TH, CCK, VIP, PHI, NPY, 5HT, GAL, or CGRP that likely modulate the activity of SCG preganglionic neurons, thus regulating overall SCG function.

In conclusion, this is the first evidence of such a neurochemical complexity of IML preganglionic sympathetic neurons supplying mammalian SCG. It might be speculated that such complexity is indispensable to SCG activity and, as such, likely contributes to the central role of SCG in numerous crucial physiological and metabolic functions. The findings of our studies underscore the importance of SCG in the autonomic nervous system and lay the foundation for future translational and clinical studies.

Acknowledgments This work was supported by UWM 1501.801 (JW) grant funding. The funders had no role in study design, data collection and analysis, decision to publish, or preparation of the manuscript. The authors would like to thank Prof. Mariusz Majewski for his research insight and Dr. Robert Crayton and Mr. David Babcock for the English language proofreading. The authors declare no conflict of interest. 
Open Access This article is distributed under the terms of the Creative Commons Attribution License which permits any use, distribution, and reproduction in any medium, provided the original author(s) and the source are credited.

\section{References}

Arbab MA, Wiklund L, Svendgaard NA (1986) Origin and distribution of cerebral vascular innervation from superior cervical, trigeminal and spinal ganglia investigated with retrograde and anterograde WGAHRP tracing in the rat. Neuroscience 19:695-708

Barinka F, Druga R (2010) Calretinin expression in the mammalian neocortex: a review. Physiol Res 59:665-677

Beaudet MM, Braas KM, May V (1998) Pituitary adenylate cyclase activating polypeptide (PACAP) expression in sympathetic preganglionic projection neurons to the superior cervical ganglion. $\mathrm{J}$ Neurobiol 36:325-336

Blottner D, Baumgarten HG (1992) Nitric oxide synthetase (NOS)-containing sympathoadrenal cholinergic neurons of the rat IML-cell column: evidence from histochemistry, immunohistochemistry, and retrograde labeling. J Comp Neurol 316:45-55

Braas KM, May V (1999) Pituitary adenylate cyclase-activating polypeptides directly stimulate sympathetic neuron neuropeptide Y release through PAC(1) receptor isoform activation of specific intracellular signaling pathways. J Biol Chem 274:27702-27710

Burnett AL, Saito S, Maguire MP, Yamaguchi H, Chang TS, Hanley DF (1995) Localization of nitric oxide synthase in spinal nuclei innervating pelvic ganglia. J Urol 153:212-217

Calka J, Zalecki M, Arciszewski MB (2008) Co-localisation of NOS-and ChAT-immunoreactivity in the spinal autonomic nuclei of the pig. An immunocytochemical study. Bull Vet Inst Pulawy 52:635-641

Całka J, Franke-Radowiecka A, Załecki M, Lakomy M (2008) Evidence for coexistence of choline acetyltransferase (ChAT)-and calcitonin gene-related peptide (CGRP)-immunoreactivity in the thoracolumbar and sacral spinal cord neurons of the pig. Pol J Vet Sci 12:61-67

Cardinali DP, Vacas MI, Gejman PV, Pisarev MA, Barontini M, Boado RJ, Juvenal GJ (1983) The sympathetic superior cervical ganglia as "little neuroendocrine brains". Acta Physiol Lat Am 33:205-221

Cassaglia PA, Griffiths RI, Walker AM (2008) Sympathetic nerve activity in the superior cervical ganglia increases in response to imposed increases in arterial pressure. Am J Physiol Regul Integr Comp Physiol 294:R1255-R1261

Chandra R, Liddle RA (2007) Cholecystokinin. Curr Opin Endocrinol Diabetes Obes 14:63-67

Chiba T, Masuko S (1987) Synaptic structure of the monoamine and peptide nerve terminals in the intermediolateral nucleus of the guinea pig thoracic spinal cord. J Comp Neurol 262:242-255

Chiba T, Masuko S (1989) Coexistence of varying combinations of neuropeptides with 5-hydroxytryptamine in neurons of the raphe pallidus et obscurus projecting to the spinal cord. Neurosci Res 7: $13-23$

Chung K, Briner RP, Carlton SM, Westlund KN (1989) Immunohistochemical localization of seven different peptides in the human spinal cord. J Comp Neurol 280:158-170

Corns RA, Boolaky UV, Santer RM (2000) Decreased calbindin-D28k immunoreactivity in aged rat sympathetic pelvic ganglionic neurons. Neurosci Lett 292:91-94

Dalsgaard CJ, Elfvin LG (1979) Spinal origin of preganglionic fibers projecting onto the superior cervical ganglion and inferior mesenteric ganglion of the guinea pig, as demonstrated by the horseradish peroxidase technique. Brain Res 172:139-143

Ding C, Walcott B, Keyser KT (2003) Sympathetic neural control of the mouse lacrimal gland. Invest Ophthalmol Vis Sci 44:1513-1520
Edwards SL, Anderson CR, Southwell BR, McAllen RM (1996) Distinct preganglionic neurons innervate noradrenaline and adrenaline cells in the cat adrenal medulla. Neuroscience 70:825-832

Eiden LE (1998) The cholinergic gene locus. J Neurochem 70: $2227-2240$

Elfvin LG, Holmberg K, Emson P, Schemann M, Hokfelt T (1997) Nitric oxide synthase, choline acetyltransferase, catecholamine enzymes and neuropeptides and their colocalization in the anterior pelvic ganglion, the inferior mesenteric ganglion and the hypogastric nerve of the male guinea pig. J Chem Neuroanat 14:33-49

Foster JA, Phelps PE (2000) Neurons expressing NADPH-diaphorase in the developing human spinal cord. J Comp Neurol 427:417-427

Gibbins IL, Hoffmann B, Morris JL (1998) Peripheral fields of sympathetic vasoconstrictor neurons in guinea pigs. Neurosci Lett 248:89-92

Girard BM, Keller ET, Schutz KC, May V, Braas KM (2004) Pituitary adenylate cyclase activating polypeptide and $\mathrm{PAC} 1$ receptor signaling increase Homer 1a expression in central and peripheral neurons. Regul Pept 123:107-116

Goadsby PJ (2013) Autonomic nervous system control of the cerebral circulation. Handb Clin Neurol 117:193-201

Gonkowski S, Rychlik A, Całka J (2013) Pituitary adenylate cyclase activating peptide-27-like immunoreactive nerve fibers in the mucosal layer of canine gastrointestinal tract in physiology and during inflammatory bowel disease. Bull Vet Inst Pulawy 57:375-380

Grigorean VT, Sandu AM, Popescu M, Iacobini MA, Stoian R, Neascu C, Strambu V, Popa F (2009) Cardiac dysfunctions following spinal cord injury. J Med Life 2:133-145

Grkovic I, Anderson CR (1997) Calbindin D28K-immunoreactivity identifies distinct subpopulations of sympathetic pre- and postganglionic neurons in the rat. J Comp Neurol 386:245-259

Hagl CI, Wink E, Scherf S, Heumuller-Klug S, Hausott B, Schafer KH (2013) FGF2 deficit during development leads to specific neuronal cell loss in the enteric nervous system. Histochem Cell Biol 139:47-57

Huerta JJ, Nori S, Llamosas MM, Vazquez MT, Bronzetti E, Vega JA (1996) Calretinin immunoreactivity in human sympathetic ganglia. Anat Embryol (Berl) 194:373-378

Ichikawa T, Shimizu T (1998) Organization of choline acetyltransferasecontaining structures in the cranial nerve motor nuclei and spinal cord of the monkey. Brain Res 779:96-103

Jensen I, Llewellyn-Smith IJ, Pilowsky P, Minson JB, Chalmers J (1995) Serotonin inputs to rabbit sympathetic preganglionic neurons projecting to the superior cervical ganglion or adrenal medulla. $\mathrm{J}$ Comp Neurol 353:427-438

Klimaschewski L, Benndorf K, Kirchmair R, Fischer-Colbrie R, Heym C (1995) Secretoneurin-immunoreactivity in nerve terminals apposing identified preganglionic sympathetic neurons in the rat: colocalization with substance $\mathrm{P}$ and enkephalin. J Chem Neuroanat 9:55-63

Klimaschewski L, Hauser C, Heym C (1996) PACAP immunoreactivity in the rat superior cervical ganglion in comparison to VIP. Neuroreport 7:2797-2801

Krassioukov A (2009) Autonomic function following cervical spinal cord injury. Respir Physiol Neurobiol 169:157-164

Lechin F, Dijs B, Pardey-Maldonado B (2013) Insulin versus glucagon crosstalk: central plus peripheral mechanisms. Am J Ther 20:349-362

Lingappa JR, Zigmond RE (2013) Limited recovery of pineal function after regeneration of preganglionic sympathetic axons: evidence for loss of ganglionic synaptic specificity. J Neurosci 33:4867-4874

Llewellyn-Smith IJ, Martin CL, Minson JB, Pilowsky PM, Arnolda LF, Basbaum AI, Chalmers JP (1997) Neurokinin-1 receptorimmunoreactive sympathetic preganglionic neurons: target specificity and ultrastructure. Neuroscience 77:1137-1149

Llewellyn-Smith IJ, Martin CL, Minson JB (2002) Glutamate and GABA content of calbindin-immunoreactive nerve terminals in the rat intermediolateral cell column. Auton Neurosci 98:7-11 
Lopez-Figueroa MO, Ravault JP, Cozzi B, Moller M (1996) Presence of nitric oxide synthase in the sheep pineal gland: an experimental immunohistochemical study. Neuroendocrinology 63:384-392

Markham JA, Vaughn JE (1990) Ultrastructural analysis of choline acetyltransferase-immunoreactive sympathetic preganglionic neurons and their dendritic bundles in rat thoracic spinal cord. Synapse 5:299-312

May V, Braas KM (1995) Pituitary adenylate cyclase-activating polypeptide (PACAP) regulation of sympathetic neuron neuropeptide $\mathrm{Y}$ and catecholamine expression. J Neurochem 65:978-987

May V, Beaudet MM, Parsons RL, Braas KM (2000) PACAP modulates rat sympathetic neuron depolarization through IP3. Ann N Y Acad Sci 921:186-194

Merriam LA, Baran CN, Girard BM, Hardwick JC, May V, Parsons RL (2013) Pituitary adenylate cyclase 1 receptor internalization and endosomal signaling mediate the pituitary adenylate cyclase activating polypeptide-induced increase in guinea pig cardiac neuron excitability. J Neurosci 33:4614-4622

Morona R, Lopez JM, Gonzalez A (2006) Calbindin-D28k and calretinin immunoreactivity in the spinal cord of the lizard Gekko gecko: colocalization with choline acetyltransferase and nitric oxide synthase. Brain Res Bull 69:519-534

Murphy SM, McAllen R, Campbell GD, Howe PR, Anderson CR (2003) Re-establishment of neurochemical coding of preganglionic neurons innervating transplanted targets. Neuroscience 117:347-360

Ninomiya T, Vuillemin M, Walter-Barakat I, Winking H, Pexieder T, Droz B (1993) Mouse fetal trisomy 13 and hypotrophy of the spinal cord: effect on calbindin-D28k and calretinin expressed by neurons of the spinal cord and dorsal root ganglia. Neuroscience 57:1109-1120

Oda Y (1999) Choline acetyltransferase: the structure, distribution and pathologic changes in the central nervous system. Pathol Int 49:921-937

Okamura H, Umehara K, Tadaki N, Hisa Y, Esumi H, Ibata Y (1995) Sympathetic preganglionic neurons contain nitric oxide synthase and project to the superior cervical ganglion: combined application of retrograde neuronal tracer and NADPH-diaphorase histochemistry. Brain Res Bull 36:491-494

Olesen M, Sottimano C, Holst JJ, Nielsen OV (1984) Autonomic nervous control of gastric somatostatin and gastrin release. Scand J Gastroenterol Suppl 89:127-129

Pearson J, Pytel BA (1978) Quantitative studies of sympathetic ganglia and spinal cord intermedio-lateral gray columns in familial dysautonomia. J Neurol Sci 39:47-59

Petras JM, Faden AI (1978) The origin of sympathetic preganglionic neurons in the dog. Brain Res 144:353-357

Popa C, Popa F, Grigorean VT, Onose G, Sandu AM, Popescu M, Burnei G, Strambu V, Sinescu C (2010) Vascular dysfunctions following spinal cord injury. J Med Life 3:275-285

Prast H, Philippu A (2001) Nitric oxide as modulator of neuronal function. Prog Neurobiol 64:51-68

Prast H, Fischer H, Werner E, Werner-Felmayer G, Philippu A (1995) Nitric oxide modulates the release of acetylcholine in the ventral striatum of the freely moving rat. Naunyn Schmiedebergs Arch Pharmacol 352:67-73

Ren K, Ruda MA (1994) A comparative study of the calcium-binding proteins calbindin-D28K, calretinin, calmodulin and parvalbumin in the rat spinal cord. Brain Res Brain Res Rev 19:163-179

Reuss MH, Reuss S (2001) Nitric oxide synthase neurons in the rodent spinal cord: distribution, relation to substance $P$ fibers, and effects of dorsal rhizotomy. J Chem Neuroanat 21:181-196

Rioux F, Kérouac R, St-Pierre S (1981) Somatostatin: interaction with the sympathetic nervous system in guinea pigs. Neuropeptides 1:319-327
Roy A, Derakhshan F, Wilson RJ (2013) Stress peptide PACAP engages multiple signaling pathways within the carotid body to initiate excitatory responses in respiratory and sympathetic chemosensory afferents. Am J Physiol Regul Integr Comp Physiol 304: R1070-R1084

Sasek CA, Baldwin C, Zigmond RE (1991) Distribution of vasoactive intestinal peptide- and peptide histidine isoleucine amide-like immunoreactive neurons and fibers in the thoracic spinal cord of the rat. Brain Res 567:159-164

Schmidt WE, Schenk S, Nustede R, Holst JJ, Folsch UR, Creutzfeldt W (1994) Cholecystokinin is a negative regulator of gastric acid secretion and postprandial release of gastrin in humans. Gastroenterology 107:1610-1620

Schroder HD (1983) Localization of cholecystokininlike immunoreactivity in the rat spinal cord, with particular reference to the autonomic innervation of the pelvic organs. J Comp Neurol 217:176-186

Schutz B, Weihe E, Eiden LE (2001) Independent patterns of transcription for the products of the rat cholinergic gene locus. Neuroscience 104:633-642

Schwaller B (2014) Calretinin: from a "simple" Ca buffer to a multifunctional protein implicated in many biological processes. Front Neuroanat 8:3

Tan CK, Tang FR, Ling EA (1996) Ultrastructural localization of substance P-like immunoreactivity in the intermediolateral column of spontaneously hypertensive rats and Wistar-Kyoto rats. Histol Histopathol 11:303-311

Tangkrisanavinont V (1984) Adrenergic control of lacrimal secretion in rabbits. Life Sci 34:2373-2378

Tanida M, Hayata A, Shintani N, Yamamoto N, Kurata Y, Shibamoto T, Morgan DA, Rahmouni K, Hashimoto H (2013) Central PACAP mediates the sympathetic effects of leptin in a tissue-specific manner. Neuroscience 238:297-304

Van Op den bosch J, Van Nassauw L, Van Marck E, Timmermans JP (2009) Somatostatin modulates mast cell-induced responses in murine spinal neurons and satellite cells. Am J Physiol Gastrointest Liver Physiol 297:G406-G417

Weihe E, Eiden LE (2000) Chemical neuroanatomy of the vesicular amine transporters. FASEB J 14:2435-2449

Wojtkiewicz J, Juranek JK, Kowalski I, Bladowski M, Calka J, Majewski M (2011) Immunohistochemical characterization of superior cervical ganglion neurons supplying porcine parotid salivary gland. Neurosci Lett 500:57-62

Wojtkiewicz J, Rowniak M, Gonkowski S, Crayton R, Majewski M, Robak A, Bialkowska J, Barczewska M (2012) Proliferative enteropathy (PE)-induced changes in the calbindin-immunoreactive (CBIR) neurons of inferior mesenteric ganglion supplying the descending colon in the pig. J Mol Neurosci 48:757-765

Yamamoto K, Senba E, Matsunaga T, Tohyama M (1989) Calcitonin gene-related peptide containing sympathetic preganglionic and sensory neurons projecting to the superior cervical ganglion of the rat. Brain Res 487:158-164

Yau JI, Wu JJ, Liu JC (1991) Origins of the afferent fibers to the cat superior cervical ganglion. Proc Natl Sci Counc Repub China B 15:1-7

Young JB, Burgi-Saville ME, Burgi U, Landsberg L (2005) Sympathetic nervous system activity in rat thyroid: potential role in goitrogenesis. Am J Physiol Endocrinol Metab 288:7

Zavros Y, Fleming WR, Hardy KJ, Shulkes A (1998) Regulation of fundic and antral somatostatin secretion by CCK and gastrin. Am J Physiol 274:G742-G750 